\title{
Artigo/Article
}

\section{Padronização e uso de um método imunoenzimático que utiliza células infectadas como antígeno no diagnóstico rotineiro do dengue}

\author{
Standardization and use of an immunoenzymatic method using infected cells as antigens in \\ routine diagnosing of dengue
}

Luzia Aparecida Costa Barreira ${ }^{1}$, Alex Martins Machado ${ }^{1}$, Victor Hugo Aquino ${ }^{2}$, Soraya Jabur Badra ${ }^{1}$ e Luiz Tadeu Moraes Figueiredo ${ }^{1}$

\section{RESUMO}

Introdução: Este trabalho mostra a padronização e o uso do método imunoenzimático utilizando células infectadas como antígeno (EIA-ICC) no diagnóstico sorológico rotineiro do dengue. Métodos: Na otimização do teste, com a dose de $1.000 \mathrm{TCID}_{50}$ de vírus do dengue tipo 3 (DENV-3), foram utilizadas 100.000 células C636 infectadas 1000 TCID $_{50}$ (DENV-3). Resultados: Os resultados obtidos com EIA-ICC foram comparados com o kit comercial de dengue HUMAN. Os resultados foram altamente coincidentes; o EIA-ICC mostrou-se moderadamente sensível e com alta especificidade. $O$ teste foi usado no diagnóstico sorológico de 1.797 amostras sorológicas de casos suspeitos de dengue durante a epidemia de Ribeirão Preto, em 2006. Na avaliação sorológica, 228 amostras foram positivas para IgM contra DENV-3, e 235 amostras foram positivas para IgG contra DEV-3, e em 35 amostras detectou-se positividade para IgM e IgG. Conclusões: O EIA-ICC mostrou-se confiável e simples sendo adequado ao diagnóstico sorológico do dengue.

Palavras-chaves: Diagnóstico. Dengue. Ensaio imunoenzimático usando células como antígeno.

\begin{abstract}
Introduction: This paper show the standardization and use of the immunoenzymatic method using infected cells as antigens (EIA-ICC) for routine serological diagnosing of dengue. Methods: In optimizing the test, a dose of $1,000 \mathrm{TCID}_{50}$ of dengue type 3 virus (DENV-3) was used, and 100,000 C636 cells infected with 1,000 TCID ${ }_{50}$ (DENV-3) were used. Results: The results obtained with EIA-ICC were compared with the HUMAN commercial dengue kit. The results were highly concordant. The EIA-ICC showed moderate sensitivity and high specificity. The test was used for serologically diagnosing 1,797 blood samples from suspected dengue cases during the 2006 epidemic in Ribeirao Preto. From the serological evaluation, 228 samples were positive for IgM against DENV-3; 235 samples were positive for IgG against DENV-3; and 35 samples were positive for both IgG and IgM. Conclusions: EIA-ICC was shown to be reliable and simple, and suitable for serologically diagnosing dengue.
\end{abstract}

Key-words: Diagnosis. Dengue. Immunoenzymatic assay using cells as antigens.

1. Centro de Pesquisa em Virologia, Faculdade de Medicina de Ribeirão Preto, Universidade de São Paulo. Ribeirão Preto, SP. 2. Faculdade de Ciências Farmacêuticas de Ribeirão Preto, Universidade de São Paulo. Ribeirão Preto, SP.

Endereço para Correspondencia: Dra Luzia Aparecida Costa Barreira. Centro de Pesquisa em Virologia/ FMRP/USP. Av. Bandeirantes 3900, Monte Alegre, 14040-901 Ribeirão Preto, SP.

Tel: 55 16 3602-3072; Fax: 55 16 3602-3376.

e-mail: luziabarreira@usp.br

Recebido para publicação em 29/07/2009

Aceito em 11/03/2010

\section{INTRODUÇÃO}

Os vírus do dengue (DENV) pertencem ao gênero Flavivirus, da família Flaviviridae. O dengue é considerado a mais importante arbovirose que afeta o homem em termos de morbidade e mortalidade ${ }^{1}$. Os Flavivirus do dengue possuem o homem como parte de seu ciclo mantenedor e um mosquito antropofílico como vetor, o Aedes aegypti. O dengue é também, importante problema de saúde pública no Brasil, que tem a maior parte da população vivendo em áreas urbanas de tamanho médio e grandes cidades, nas regiões sudeste e nordeste, locais infestados pelo Aedes aegypti. Isto, aliado ao clima tropical e à desorganização urbana, dentre vários fatores, fez com que o dengue se tornasse endêmico no país ${ }^{2}$.

Em 1990, surgiram na Cidade de Ribeirão Preto os primeiros casos autóctones de dengue, causados por DENV-1 ${ }^{3}$. Desde então, vem circulando em Ribeirão Preto os DENV-2 e DENV-3 ${ }^{2,4}$. Durante a epidemia de dengue em 2006, o Centro de Pesquisa em Virologia da Faculdade de Medicina de Ribeirão Preto, Universidade de São Paulo (CPV-FMRPUSP) cooperou com a Secretaria Municipal de Saúde local realizando o diagnóstico laboratorial de dengue em pacientes atendidos pela rede básica de saúde e resultados parciais destes testes são exibidos neste trabalho.

Métodos sorológicos são importantes no diagnóstico das infecções por dengue. Dentre os métodos sorológicos, em nosso meio, são mais comumente utilizados métodos imunoenzimáticos que permitem detectar IgM específica associada à infecção aguda por dengue e dentre estes, destaca-se o MAc-ELISA ${ }^{4,5}$. Para o presente trabalho, visando à detecção de anticorpos IgM e IgG contra dengue, destacamos um método imunoenzimático que utiliza culturas celulares infectadas como antígeno no teste (EIA-ICC - enzyme immunoassay on infected cultured cells $)^{6,7}$. 


\section{MÉTODOS}

\section{Padronização do EIA-ICC}

Células $\mathrm{C} 6 / 36$ foram cultivadas em frascos estéreis de poliestireno (CORNING - USA) contendo meio nutriente de Leibowitz (L-15), $10 \%$ de soro bovino fetal, $10 \%$ de solução de fosfato de triptose, $100 \mathrm{U} / \mathrm{ml}$ de penicilina e $100 \mu \mathrm{g} / \mathrm{mL}$ estreptomicina. As células foram mantidas a $28^{\circ} \mathrm{C}$, até formarem monocamadas confluentes ${ }^{2,7,8}$.

Utilizou-se no EIA-ICC o DENV-3 da estirpe BR/RP1/03 (vírus isolado em 2003 no CPV-FMRP-USP). A semente viral, com título $10^{6,8} \mathrm{TCID}_{50} / \mathrm{mL}$, foi diluída 158 vezes em meio L- 15 o que permitia inocular $10^{3,31} \mathrm{TCID}_{50} / 50 \mu \mathrm{L}$ (ou 2.041 partículas $\mathrm{TCID}_{50}$ ) do vírus em cada frasco ${ }^{7,9}$. Os frascos, após descarte do meio de cultivo e inoculação viral, foram agitados a cada 15 minutos (min) e mantidos a $28^{\circ} \mathrm{C}$, por 1 hora (h). Em seguida, adicionavam-se ao frasco $15 \mathrm{~mL}$ do meio $\mathrm{L} 15 \mathrm{com} 2 \%$ de soro fetal bovino inativado, $10 \%$ da solução de fosfato de triptose, $100 \mathrm{U} / \mathrm{ml}$ de penicilina e $100 \mu \mathrm{g} / \mathrm{mL}$ estreptomicina e este era incubado a $28^{\circ} \mathrm{C}$. Outro frasco de células $\mathrm{C6} / 36$, da mesma partida, era mantido não infectado, para ser usado como controle-negativo no EIA-ICC. Os frascos infectados foram mantidos em ambiente úmido, a $28^{\circ} \mathrm{C}$, por 6 dias $^{2}$.

Para confirmar a infecção por DENV-3, as células eram transferidas para lâminas de vidro nos círculos delimitados (spots), fixadas e submetidas a um teste de imunofluorescência indireta ${ }^{5}$.

\section{Preparo da microplaca}

Microplacas estéreis de poliestireno com 96 orifícios de fundo chato (CORNING, USA), tiveram colunas de orifícios alternadas que foram inoculadas com células C6/36 infectadas com DENV-3. Às outras colunas de orifícios, adicionavam-se células C6/36 não infectadas como controles negativos no teste. Para tanto, raspavamse as monocamadas celulares contidas nos frascos e rompiam-se os grumos celulares por pipetagem. As células foram contadas em câmara de Neubauer e, inicialmente, adicionaram-se aos orifícios das placas 50.000, 100.000, 200.000, 400.000, 800.000 células em 100 $\mu \mathrm{L}$ do meio de cultivo, para determinação da quantidade celular mais adequada ao EIA-ICC de DENV-3. Em seguida, promovia-se uma leve agitação, para que as células se depositassem homogeneamente no fundo dos orifícios. As placas eram incubadas até o dia seguinte, em ambiente úmido, a $28^{\circ} \mathrm{C}$ e tiveram suas células fixadas ao fundo dos orifícios pela adição de $100 \mu \mathrm{L}$ de solução formalina tamponada a $10 \%$ ( $10 \%$ de formaldeído em $100 \mathrm{~mL}$ de água, $6,5 \mathrm{~g}$ de fosfato de sódio dibásico anidro, $4 \mathrm{~g}$ de fosfato de sódio monobásico e água destilada q.s.p.900mL, pH7,4). Em continuação, as placas eram incubadas por 12 a $18 \mathrm{~h}$, em atmosfera úmida, a $4^{\circ} \mathrm{C}$, lavadas por 2 vezes com solução de Tween, $1 / 20.000$ em PBS (PBS-T) e secas por emborcamento sobre papel absorvente. Nesta fase, as microplacas, já prontas para uso, foram utilizadas imediatamente no teste ou, armazenadas a $-20^{\circ} \mathrm{C}$ em recipiente plástico ${ }^{2,4,6}$.

\section{Realização do EIA-ICC}

Para o EIA-ICC, adicionavam-se aos orifícios da placa $200 \mu \mathrm{L}$ de solução bloqueadora de ruído (background), foi utilizada solução de leite em pó desnatado a 10\% em PBS (LPD10\%).

Como solução diluente do teste, foi utilizada solução de albumina bovina a $0,5 \%$ em PBS. Na continuação, lavavam-se os orifícios da placa por 3 vezes com PBS-T e adicionavam-se a orifícios infectados e não infectados (orifícios da coluna impar e da coluna par da microplaca) os soros à serem testados. Também, nos testes com a placa de titulação viral, bem como, naqueles realizados para determinação do número de células, da solução fixadora e da solução bloqueadora, utilizaram-se MIAFs anti-DENV (fluido ascítico imune de camundongo - MIAF). Os MIAFs eram diluídos $1 / 200$, no diluente do teste em solução de albumina bovina a $0,5 \%$ em PBS. Adicionavamse $100 \mu$ l por orifício da placa. Ainda, as seguintes diluições de soros humanos positivos para dengue, $1 / 50,1 / 100,1 / 150$ e $1 / 200$, foram avaliadas visando à escolha de uma diluição ideal a ser usada na triagem preliminar de uma grande quantidade de soros. Os soros foram adicionados, $100 \mu \mathrm{l}$ por orifício e as placas, incubadas por $1 \mathrm{~h} \mathrm{a} 37^{\circ} \mathrm{C}$. Em continuação, as placas foram lavadas por 4 vezes com PBS-T e então, adicionaram-se aos orifícios, dependendo do caso, $100 \mu \mathrm{L}$ do conjugado de imunoglobulina caprina anti-IgM ou anti-IgG humano, ambas conjugadas à peroxidase (SIGMA, USA), na diluição 1/2.000, em diluente do teste. Novamente, as placas foram incubadas por $1 \mathrm{~h}$, a $37^{\circ} \mathrm{C}$, lavadas 4 vezes com PBS-T e finalmente, adicionava-se o substrato oxidante ABTS (KPL, USA), $100 \mu \mathrm{L}$ por orifício. Após incubação por $30 \mathrm{~min}, 3^{\circ} \mathrm{C}$, para desenvolvimento da cor verde nos orifícios em que havia soro com anticorpo contra dengue, bloqueavase a reação por acidificação, adicionando $50 \mu \mathrm{l}$ de uma solução $3 \mathrm{M}$ de HCL aos orifícios. Em seguida, a placa era lida visualmente e também em espectrofotômetro leitor de ELISA (Titertek, Finlândia) com filtro de $405 \mathrm{~nm}$. O cálculo do ponto de corte (cut-off) foi feito com base na média das densidades óticas (DOs) obtidas no espectrofotômetro em pelo menos 8 orifícios contendo células não infectadas. A esta média acrescentavam-se 3 desvios-padrão o que determinava ao teste uma especificidade superior a $99 \%$. Valores acima do ponto de corte foram considerados positivos. Aspecto da microplaca de EIA-ICC é mostrado na Figura 1.

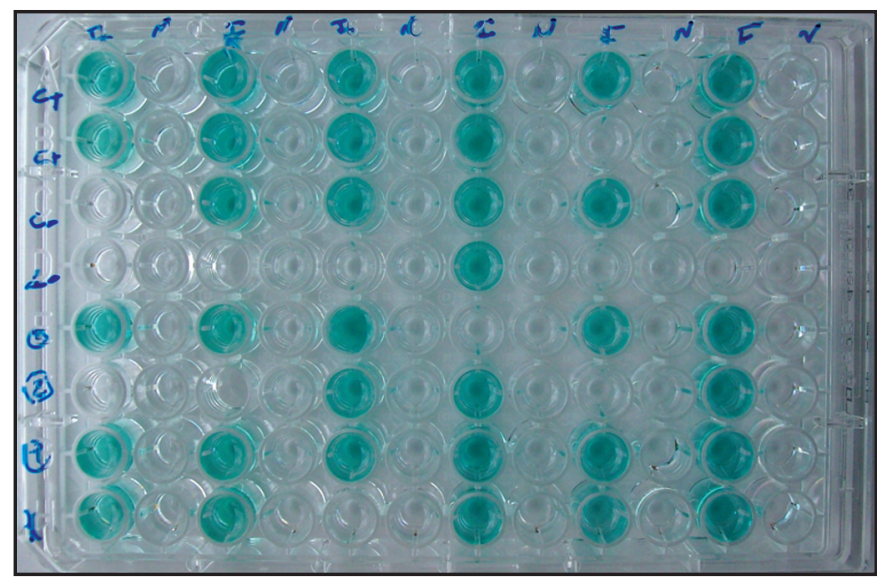

FIGURA 1 - Aspecto de uma microplaca de EIA-ICC para DENV-3, com soro imune de camundongo contra DENV-3 adicionados aos orifícios coloridos, na diluição 1/100 e mostrando resultado fortemente positivo. As colunas de orifícios ímpares contendo células infectadas com DENV-3 aparecem em verde, contrastando com as colunas contendo células não infectadas nas quais não se observa cor.

Soros de pacientes da epidemia de dengue em Ribeirão Preto, 2006, testados por EIA-ICC. Foram analisados 1.797 soros por EIA-ICC para DENV-3. Estes soros eram de pacientes, de ambos os sexos e de todas as faixas etárias, com suspeita clínica de dengue e que se apresentaram para atendimento médico em Unidades Básicas de Saúde (UBS) da cidade de Ribeirão Preto, em março e abril de 2006. Os sangues foram colhidos por punção intravenosa e encaminhados ao CPVFMRP-USP para confirmação laboratorial de dengue. Estes sangues 
foram colhidos 5 ou mais dias apos o início dos sintomas de dengue, tendo sido, por esta razão, indicados para diagnóstico sorológico e armazenados a $-20^{\circ} \mathrm{C}$ até a realização do teste sorológico.

\section{Ética}

Este trabalho, realizado no CPV-FMRP-USP, foi aprovado pela Comissão de Ética em Pesquisa Humana do HCFMRP-USP, no CAAE-0209.0.004.000-06, no Oficio n ${ }^{\circ}$ 2440/2006 CEP/MGV e no Processo HCRP n ${ }^{\circ}$ 9390/2006.

\section{RESULTADOS}

Comparação de resultados por EIA-ICC e teste HUMAN. Comparou-se resultados obtidos pelo EIA-ICC, na detecção de IgM contra DENV-3, com resultados da detecção de IgM pelo teste comercial HUMAN de diagnóstico sorológico do dengue. Escolheuse este teste para comparação por ter uso rotineiro em nosso meio e tratar-se de um ELISA indireto que detecta IgG e/ou IgM, como o EIA-ICC. Foram comparados resultados de 85 soros de pacientes com suspeita clínica de dengue selecionados aleatoriamente. Destes, 17 soros exibiram resultado positivo por ambos os testes, 6 apenas pelo EIA-ICC e 5 apenas pelo HUMAN.

Portanto, com base no teste HUMAN o EIA-ICC mostrou sensibilidade de $74 \%$, especificidade de $92 \%$, o valor preditivo positivo foi de $77 \%$, o valor preditivo negativo de $90 \%$ e a acurácia de $87 \%$. Assim, o EIA-ICC quando comparado ao teste HUMAN, mostrou-se moderadamente sensível e com moderado valor preditivo positivo, mostrou alta especificidade e boa acurácia.

Também, como parte da análise comparativa do EIA-ICC para DENV-3 com o teste HUMAN, fez-se análise estatística pelo teste Kappa, evidenciando um índice geral de 0,675, um intervalo de confiança (IC) de 95\%, com valor superior de 0,876 e inferior de 0,474 e p $<0,001$, o que sugere uma alta concordância entre os testes.

Diagnóstico de DENV-3 por EIA-ICC na epidemia de Ribeirão Preto, 2006. Um total de 1.797 amostras séricas de pacientes com suspeita clínica de dengue, após a realização do teste em 228 amostras detectou-se IgM contra DENV-3 (positividade de 12,7\%). Detectou-se IgG para DENV-3 em 235 amostras (positividade de 13,1\%). Em 35 amostras detectou-se IgG e IgM para DENV-3 (positividade de 1,9\%). Estes resultados são mostrados na Figura 2.

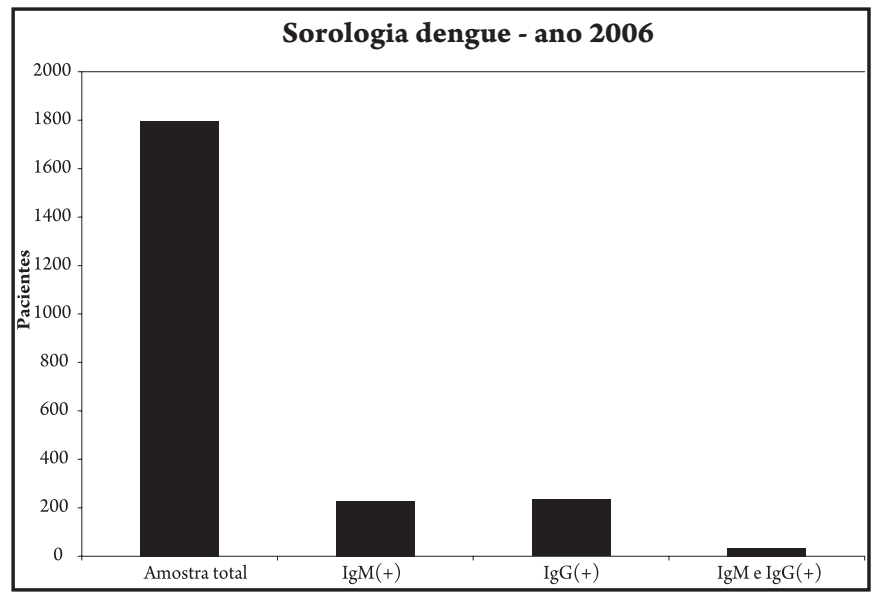

FIGURA 2 - Número de soropositivos por detecção de IgM e IgG para DENV-3 no EIA-ICC.
Dos 815 participantes do sexo masculino cujos soros foram testados por EIA-ICC, 86 tiveram IgM reagente para DENV-3, positividade de $10,5 \%$. Da mesma forma, de 982 participantes do sexo feminino encontraram-se 142 positivos para IgM, positividade de $14.5 \%$. Portanto, a positividade de IgM para DENV-3 foi significantemente maior entre as mulheres $(\mathrm{p}=0,007)$.

Quanto à idade, os participantes foram divididos 6 faixas etárias como mostra a Figura 3. Foi significantemente maior a soro positividade de IgM para dengue entre mulheres de 2 a 15 anos $(\mathrm{p}<0,01)$ e de 16 a 30 anos $(\mathrm{p}<0,01)$.

Observa-se na Tabela 1 a positividade sérica para DENV-3 (IgM) segundo dias de doença no momento da coleta amostral.

O período de 5 a 12 dias agregou 99,1\% dos soropositivos IgM para DENV-3. Observaram-se diferenças significantes quando compararam-se pelo teste $\mathrm{Z}$, para diferença de duas proporções, as faixas de 5 a 8 dias e 9 a 10 dias $(\mathrm{p}<0,001)$.

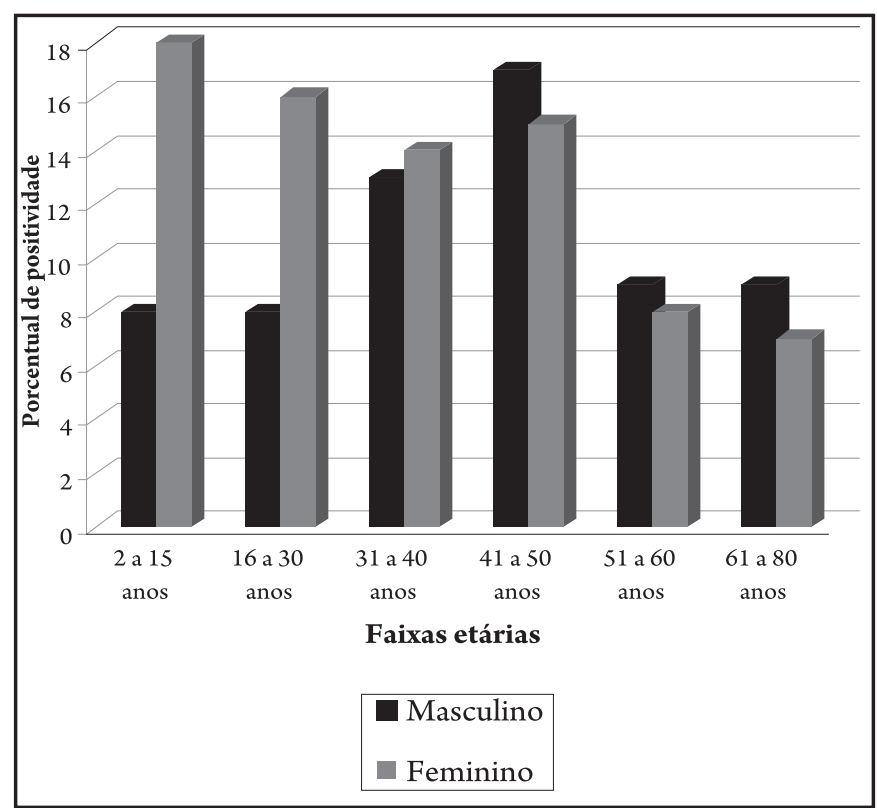

FIGURA 3 - Positividade de anticorpos IgM para DENV-3 detectados por EIAICC nos 1.797 participantes do estudo segundo sexo e faixa etária.

TABELA 1 - Dias de doença e positividade de IgM sérico para DENV-3 nos pacientes.

\begin{tabular}{lrrrrrr}
\hline & \multicolumn{2}{c}{$\begin{array}{c}\text { Total de amostras } \\
\text { para sorologia }\end{array}$} & & \multicolumn{2}{c}{$\begin{array}{c}\text { Pacientes com IgM } \\
\text { positiva DENV3 }\end{array}$} \\
\cline { 2 - 3 } Dias de doença & $\mathrm{n}^{-}$ & $\%$ & & $\mathrm{n}^{\circ}$ & $\%$ \\
\hline 5 & 38 & 2,1 & & 0 & 0 \\
6 & 46 & 2,6 & & 13 & 5,7 \\
7 & 304 & 16,9 & & 36 & 15,8 \\
8 & 330 & 18,4 & & 64 & 28,1 \\
9 & 298 & 16,6 & & 38 & 16,7 \\
10 & 241 & 13,4 & & 32 & 14,0 \\
11 & 215 & 12,0 & & 33 & 14,5 \\
12 & 68 & 3,8 & & 10 & 4,4 \\
13 & 30 & 1,7 & & 0 & 0 \\
\hline
\end{tabular}




\section{DISCUSSÃO}

No Brasil, os métodos laboratoriais mais utilizados no diagnóstico do dengue são os sorológicos, visando à detecção de IgM específica, após o quinto dia de doença. Dos métodos sorológicos, os mais utilizados são os imunoenzimáticos (ELISA) e dentre eles, prepondera o MAc-ELISA ${ }^{4,5,10}$.

Em 1.797 soros analisados, observou-se uma baixa positividade, apenas 428 , ou seja, $23,8 \%$ dos pacientes apresentaram anticorpos IgM para DENV-3. Isto sugere que, provavelmente, mais de 3/4 dos casos suspeitos que participaram do estudo tinham outras doenças infecciosas.

Dentre os pacientes com dengue diagnosticados por EIA-ICC, observou-se uma positividade maior entre as mulheres, fato que poderíamos explicar; porém sem comprovação, aventando que a transmissão viral se daria principalmente no domicílio.

A soropositividade para DENV-3 por EIA-ICC ocorreu entre 5 a 12 dias após o início dos sintomas da doença (99,1\% dos pacientes), como tem sido observado em outros trabalhos com o EIA-ICC e também, outros ensaios imunoenzimáticos ${ }^{2,6,7}$.

Os resultados obtidos neste trabalho, coincidem e se somam aos relatados em estudos prévios ${ }^{2,6,7,11}$, e nos permitem concluir que o EIA-ICC é um método específico e confiável no diagnóstico sorológico do dengue, possuindo, inclusive, as vantagens de ser todo desenvolvido in house, ser simples e rápido após o preparo das placas, podendo ser facilmente realizado em laboratórios com poucos recursos técnicos. Ainda, a detecção simultânea de anticorpos IgG e IgM por EIA-ICC, permitiria diagnosticar infecções primárias e secundárias por dengue o que deverá ser motivo de nossos próximos trabalhos utilizando a técnica.

\section{CONFLITO DE INTERESSE}

Os autores declaram não haver nenhum tipo de conflito de interesse no desenvolvimento do estudo.

\section{REFERÊNCIAS}

1. Gubler DJ. Current research on dengue. In: Harris KF, editor. Current topics in vector research. Springer Verlag: New York; 1987. p. 37-56.

2. Figueiredo LTM. Estudos sobre o dengue em Ribeirão Preto 1990-1993.1994.112 f. Tese de livre docência. Faculdade de Medicina de Ribeirão Preto, Universidade de SãoPaulo. Ribeirão Preto; 1994.

3. Secretaria de Estado de Saúde de São Paulo. Coordenadoria de Controle de Doenças - CCD/SCS-SP. Boletim Epidemiológico Paulista.

4. Figueiredo LTM, Owa MA, Carlucci RH, DalFabro AL, Mello NV, Capuano DM, Santili MB. Dengue serologic survey in Ribeirão Preto, São Paulo, Brazil. Bull Pan Am Health Organ 1995; 29:59-69.

5. De Paula SO, Fonseca BALF. Dengue: A Review of the Laboratory Tests a Clinician Must Know to Achieve a Correct Diagnosis. The Braz J Infec Dis 2004 8:390-398.

6. Figueiredo LTM, Shope RE. An enzyme immunoassay for dengue antibody using infected cultured cells as antigen. J Virol Methods 1987; 17:191-198.

7. Figueiredo LTM, Simões MC, Cavalcante SMB. Enzyme immunoassay for the detection of dengue IgG and IgM antibodies using infected mosquito cells as antigen. Trans Royal Soc Trop Med and Hyg 1989; 83:702-707.
8. Lima VLC, Rangel O, Andrade VR, Silveira NY, Oliveira SS, Figueiredo LTM. Dengue: inquérito populacional para pesquisa de anticorpos e vigilância virológica no Município de Campinas, São Paulo, Brasil. Cad Saude Publica $2007 ; 23: 669-680$

9. Reed LJ, Muench H. Simple method of estimating fifty percent endpoints. Amer J Hyg 1938; 27: 493-497.

10. Nogueira RMR, Schatzmayr HG, Miagostovich MP, Farias MFDB, Farias Filho JC. Virological aspects of a dengue type 1 epidemic at Rio de Janeiro. Mem Inst Oswaldo Cruz 1988; 83:219-225.

11. Figueiredo LTM, Owa MA, Carlucci RH, Oliveira L. Estudo sobreo diagnóstico laboratorial e sintomas do dengue, durante epidemia ocorrida na rgião de Ribeirão Preto, SP, Brasil. Rev Inst Med Trop São Paulo 1992; 34:121-130. 